\section{The Eclipse Photographs}

IT would have given me much pleasure to have shown $\mathrm{Mr}$. Winstanley the original negatives of the photographs of the late eclipse of the sun if he had called on me to see them, and by so doing he would have avoided falling into the mistakes which his letter contains.

At the time when the last photograph was taken the sky was perfectly clear, and unless Mr. Winstanley is in possession of exclusive information he has no right to assume that the American photograph was not taken under equally favourable conditions. Some of my photographs (which Mr. Winstanley cannot have seen) were taken through the edges of a cloud, the whole of which could be covered by the hand when held with the arm extended; and there was a perfectly cloudless sky near the sun excepting towards the east.

The imperfection in my No. 5 picture, which Mr. Winstanley's experienced eye detects, arose from the shaking of the telescope, caused by the high wind blowing at the time. Probably a single gust during the eight seconds while the plate was exposed caused the mischief, and this defect would never have been seen but for the extremely actinic power of the red prominences which leave their impression on the sensitive plate instantaneously. The moun's limb is perfectly sharp, excepting where the red prominences appear.

Let it be clearly understood that this "indifferent definition" refers to the moon's limb only; the details of the corona do not appear to have suffered; after the gusts of wind the telescope has returned to its proper position, and $\mathrm{Mr}$. Winstanley must know from experience that the image of an object giving off feeble light would not be materially injured by a slight blow given to a firmly mounted camera.

Mr. Winstanley says that "the identity of the coronal rifts in the Cadiz and Syracuse photographs is not satisfactorily conclusive." Assertion is not proof. In NATURE of March 9 I gave evidence which appeared to me to be conclusive (I need not here refer to the opinions of others who are equally satisfied), and up to the present time no counter-evidence has been pro duced.

It is not for me to defend the American photograph. In due time we shall know all about how that was produced. But has Mr. Winstanley failed to notice that the light on the moon's disc does not extend all round and all over it as it would do if caused by our atmosphere? It is chiefly on the east and west sides. We may expect the explanation of this defect when we hear how it happens that the corona in this photograph is cut off instead of extending as in all the other photographs.

I fail altogether to see the connection between the solar corona. and a lunar halo-the phenomena bear no resemblance to each other. The solar corona comes close up to the perfectly black disc of the moon. I never saw a lunar halo close up to the moon's limb. When seen through a mist or in a "sky burdened with innumerable clouds," there can be no doubt that the lunar surface is obscured by the moisture in our atmosphere.

\section{A. BROTHERS}

\section{Ocean Currents}

HAVING had occasion in the spring of 1868 to consider the subject of Ocean Currents as discussed by Captain Maury and Sir John Herschel, I was led to certain views respecting the origin of the oceanic circulation, which are briefly touched upon in a paper which appeared in the Student for July, 1868. At that time an experimental test of my theory (or rather of that portion of the theory $I$ advocated, which was, as $I$ judged, novel) occurred to me. The experiment might, I conceive, be very readily tried. It somewhat resembled that by which Dr. Carpenter illustrated lately at the Royal Institution his views respecting the influences of evaporation and polar cold ; but as I wished specially to show how the westwardly equatorial current came about, the experiment was somewhat more complex. Let the circumference of a large and shallow cylindrical basin represent the equator and the central part the north polar regions. Within this cylinder let solid matter be so placed as to represent the northern halves of the continent, in such sort that the resulting configuration would correspond to that of a map of the northern hemisphere (say on the equidistant projection). Let sea-water be poured in to represent the northern portions of the terrestrial oceans. Now to represent the Arctic ice-fields, let Iumps of ice be placed at the centre of the cylindrical vessel (they should be circled round by a wire-guard) ; and to represent the effects of equatorial heat, let a stout iron ring round and above the rim of the cylindrical vessel be heated. In this state of things the process of circulation, which actually took place in Dr. Carpenter's experiment, would take place after such modified sort as the contour of the continent nasses permitted. Now suppose that the cylindrical vessel is set in steady and somewhat slow rotation about its axis. It is clear that on the currents flowing from the pole and pole. wards, effects will be produced which precisely resemble those clue to our earth's rotation. If I am right in regarding these effects as the true cause of the direction in which the equatorial currents, the Gulf Stream, and in fact all the currents in open ocean are observed to flow, abundant evidence to that effect will be obtained. If no such evidence be obtained, the westwardly direction of the equatorial currents must, I imagine, be ascribed to the trade winds, as Franklin and Sir J. Herschel have main. tained.

In the summer of 1868 I suggested to Prof. Pepper that such a contrivance as the above, if it worked as I juclged (and still judge) that it would, would form an interesting and instructive addition to the models exhibited at the Polytechnic Institution. Dr. Carpenter has already proved that the vertical circulation takes place in an experiment of this sort. If the eastwardly and westwardly circulation takes place as I expect, the expeimental illustration of oceanic circulation would be singularly complete. The circulation in the southern hemisphere could be illustrated in like manner.

I may note here that the vast distance separating the polar from the equatorial regions must not be overlooked in theories respecting oceanic circulation. The influence of arctic cold may be paramount in very high latitudes; but equatorial evaporation must, it should seem, be the prime moving cause in tropical and sub.tropical regions.

Brighton, June 6

RICHARD A, PROCTOR

\section{Day Auroras}

I HAVE read attentively the numerous letters which have appeared in your columns on this subject; but so far as I can cliscern it seems not to have occurred to any of your correspondents that the auroral force, whatever it may be, affects every kind of cloud as well as the cirrus. On June I5, I870, at 9 A. M., I witnessed here as complete a display of auroral motions in the cirrus cloud as ever I beheld in a midnight sky; and from that clate I dismissed in my own mind all doubt as to the identity of aturoral force, whether seen by day affecting the cirrus cloud or appearing as streams and rays of light at night. On Thursday and Friday last I witnessed a configuration of cirro-stratus cloud, evidently the result of magnetic poiarisation, which I have no hesitation in characterising as auroral. There were on Thursday two poles, both in the line of the magnetic meridian; but on Friday night, at nine o'clock, only one pole in the direction of the true meridian. The phenomenon to which I refer is of very frequent occurrence, especially before a track of fine warm weather; and without at present offering a theory on the subject of auroras, I venture to class polarisations of clouds, whether cirrus or not, as arising from the same cause as luminous aurora. The transverse or dia.magnetic lines are generally as well marked in cloud auroras, and it is an interesting task to watch the transformation of cirrus cloud from the meridional to the equatorial direction. I have also noted that when these auroral lines converge towards the magnetic pole, a steady barometer and fine weather ensue; but that when the transverse or equatorial lines predominate and continue long visible, rain soon follows. These transverse lines of cloud are always lower and seem to be dia-magnetic. D. Low

Burntisland, May 22

Perhaps you will allow me to add my mite to the discussion which has been going on in your pages on the question of the visibility of the aurora in daylight.

On the 3rd of September in last year, when at Nairn in the north of Scotland, I witnessed an aurora, such as I never heard or read of, or saw before; and strangely enough it was not noticed, as far as I am aware, in any of the newspapers. I had gone down to the beach at about IO I5 P.M., and immediately noticed what appeared at first to be a kind of haze over the whole sky, which slightly dimmed the light of the stars.

For a few minutes I thought no more about it, but, happening to turn my eyes towards the zenith, there was a sight I never shall forget. A number of sheets of whitish light were con 